\title{
RESENHA \\ Saberes e ciência plural: diálogos e interculturalidade em Antropologia
}

\author{
Linda Osiris González Cárdenas ${ }^{1}$ \\ Universidade Federal do Paraná
}

MONTARDO, Deise; RUFINO, Márcia (orgs.). Saberes e ciência plural: diálogos e interculturalidade em Antropologia. Florianópolis: Editora da UFSC, 2017. 335 p. (Coleção Brasil Plural)

$\mathrm{O}$ livro "Saberes e ciência plural: Diálogos e Interculturalidade em Antropologia” faz parte da Coleção Brasil Plural, e segue a missão do Instituto Nacional de Pesquisa Brasil Plural (INCT/CNPq), que consiste em trazer a discussão a pluralidade sociocultural e ambiental do Brasil, contribuindo na elaboração de políticas sociais que correspondam com as demandas e visões das populações estudadas. Dentro desta rede de estudos participam instituições como a Universidade Federal do Amazonas (UFAM) e a Universidade Federal de Santa Catarina (UFSC), assim como institutos e pesquisadores estrangeiros. A elaboração deste livro foi resultado do Colóquio "Saberes e Ciência Plural2", onde foram apresentadas pesquisas etnográficas desenvolvidas por antropólogos e pesquisadores indígenas e não indígenas, brasileiros e estrangeiros, que destacaram outras formas de conhecimentos não científicos encontrados em campo.

O corpo do livro está composto por Prefácio, escrito por Antônio Carlos de Souza Lima, uma apresentação feita pelas organizadoras do livro Deise Lucy Oliveira Montardo e Márcia Regina Farias Rufino3, quatorze capítulos divididos em quatro subtemas, e uma breve apresentação da trajetória dos autores. Ao longo

${ }^{1}$ Mestra em Antropologia pela Universidade Federal do Paraná e bacharel em Antropologia pela Universidade Federal da Integração Latino-Americana.

2 Mais informações sobre o evento podem ser consultadas aqui: https://ufam.edu.br/noticias-bloco-esquerdo/3339coloquio-saberes-e-ciencia-plural-inicia-dialogando-sobre-pesquisas-em-antropologia

3 Ambas professoras do Departamento de Antropologia da UFAM e integrantes do Comitê Gestor do Instituto Nacional de Pesquisa Brasil Plural. 
dos capítulos procura-se refletir e propor, a partir de contextos etnográficos do Brasil, Chile, Colômbia e México, caminhos possíveis para a constituição de uma ciência plural que seja "feita a muitas mãos, redes e entrecruzamentos" (Montardo e Rufino, 2017: 11), descentralizando a produção do conhecimento dos laboratórios e gabinetes, e outorgando maior importância ao cotidiano e às experiências de vida dos interlocutores das pesquisas. Adicionalmente, a obra também contribui com a produção científica e antropológica na América Latina, transcendendo da reflexão acadêmica para a ação política4 ${ }^{4}$

A primeira parte do livro, "Coletividades específicas, redes e instituições", inicia com o capítulo "Antropologias e saúdes no plural: diálogos, engajamentos e a pesquisa interdisciplinar", escrito pela antropóloga norte-americana Esther Jean Langdon, quem comenta a partir da sua trajetória de pesquisa a formação do subcampo da Antropologia da Saúde no Brasil e na América Latina, suportado na reforma sanitária promovida pela Saúde Coletiva. Adicionalmente, Langdon constatou a diferença epistemológica e política que existe entre este campo e a Antropologia Médica Norte Americana, considerando que é adotada uma posição crítica diante do paradigma biomédico, discutindo o papel da instituição médica na sociedade, e reconhecendo a pluralidade de práticas da saúde que não podem ser reduzidas apenas a "crenças".

No capítulo "Cosmología y territorialidad entre los pueblos indígenas de Oaxaca, México", Alicia Barabas discute conceitos, imagens e mitologias compartilhadas pelas cosmologias das populações que habitam no estado mexicano de Oaxaca, que se caracterizam por serem territoriais já que "sus conceptos y prácticas están estrechamente entretejidos con los medioambientes naturalesculturales" (Barabas, 2007: 54). Ao mesmo tempo, estas cosmologias se baseiam nas relações estabelecidas entre seres humanos e extra-humanos, seguindo os lineamentos da "ética del Don" (Barabas, 2007: 56), encarregada em regular "relaciones de reciprocidad equilibrada entre personas, familias, vecinos, autoridades y comunidades, en todos los campos de la vida social"s.

Em "Você quer mesmo escutar e cantar increr cahàc-re? As classificações dos cantos de cà (Pátio) para os Ràmkôkamẽkrã/Canela", escrito por Ligia Raquel Rodrigues Soares e Odair Giraldin, é apresentada uma sistematização do universo músico-ritual dos povos timbira, condensado no sistema cancional do pátio ${ }^{6}$. Os autores reforçam a relação existente entre a prática dos Ràmkôkamẽkrãa/Canela e o conceito de ritual do antropólogo britânico Stanley Tambiah, considerado como um sistema de comunicação simbólica constituído por sequências de palavras ordenadas e atos expressados através de ações rituais.

No último capítulo da Parte I, "Educação, infância e diversidade: desafios à antropologia e às políticas públicas", são apresentados alguns resultados de pesquisas vinculadas ao projeto "Compreensões Antropológicas sobre Conhecimentos Nativos: um diálogo em rede", composto por quatro eixos: "Noções de infância e desenvolvimento infantil”, "Modos de produção e circulação de conhecimentos", "Desafios das escolas indígenas e da inclusão da diversidade no ensino superior", e "Desafios em relação às políticas públicas". Dentro destas, é discutido o papel da criança indígena e sua produção corporal e identitária, as relações estabelecidas com a alteridade, assim como entre conhecimentos indígenas e

\footnotetext{
${ }_{4}$ Conforme seria o propósito das "Antropologias Subalternas" (Oliveira, 1993), “Antropologías del Sur" (Krotz, 1993), ou "Antropologia mestiza" (Degregori \& Sandoval, 2008: 13).

5 Com isso, a autora procura distanciar-se de teorias ameríndias como o Perspectivismo ou Animismo, já que, segundo ela, estas procuram explicar as relações estabelecidas entre humanos e não humanos questionando as concepções dualistas ocidentais de natureza/cultura ou natural/sobrenatural.

${ }^{6}$ Composto pela tríade Kricape, Cà e Wyhty.
} 
científicos, e, por fim, a criação de políticas públicas em base à realidade sociocultural das populações.

No primeiro capítulo da Parte II, "Saberes e diálogos simétricos", titulado "Las identidades imaginadas: algunos problemas del diálogo intercultural en una sociedad plural", e escrito por Miguel Alberto Bartolomé, são apresentados alguns dos obstáculos para o estabelecimento de um diálogo intercultural em sociedades pluriculturais, partindo do sistema interétnico de Oaxaca, onde não existe uma separação tácita entre identidades. Para o autor, nesta situação a educação pode ser uma ferramenta útil para possibilitar uma articulação social intercultural, uma vez questione as estruturas sociais estabelecidas sob uma matriz colonial (Walsh, 2009), para não incorrer numa "manipulação simbólica" que "tiene la capacidad para construir al "otro" de acuerdo con sus propios intereses" (Bartolomé, 2017: 146).

Em "Papera Kumu: caminho de formação de xamã de leituras", o antropólogo tukano João Paulo Lima Barreto apresenta sua trajetória como pesquisador indígena dentro da antropologia, proporcionando um olhar crítico tukano sobre a ciência e sua produção. $\mathrm{O}$ autor, nos seus estudos sobre a ciência dos brancos e seu papel de "xamã especialista de livros", detectou a falta de sistematização logica dos mitos tukano para além das narrativas, que os tornasse em modelos de conhecimento para serem traduzidos e confrontados com a ciência. Neste processo, Barreto Lima conseguiu adotar uma postura reflexiva sobre os conhecimentos tukano, e sobre a forma de fazer ciência a partir de uma antropologia indígena.

No mesmo caminho, Jozileia Daniza Jasgo Inacio J. Schild, no capitulo "Ações afirmativas na pós-graduação: percepção de uma Kaingang no programa de Pós-Graduação em Antropologia Social da UFSC”, apresenta um breve panorama sobre o estabelecimento de ações afirmativas nas universidades e instituições federais brasileiras, isto a partir da sua própria experiência como estudante indígena beneficiada por esta forma de ingresso. A partir disso, a autora ressalta que o maior desafio do aluno indígena começa após o ingresso na universidade, quando deve buscar formas para permanecer dentro desta estrutura educativa, desafiando constantemente o olhar academicista que fragmenta conhecimentos e sujeitos.

No primeiro capitulo da Parte III "Socioambiente e saberes tradicionais", denominado "Da temporada da tainha: a temporalidade da paisagem", Rafael Victorino Devos, Gabriel Coutinho Barbosa e Viviane Verdana discutem a produção de lugares na paisagem costeira da cidade de Florianópolis durante a temporada de pesca da tainha. Para eles, este espaço litorâneo não é um cenário que apenas pode ser ocupado fisicamente, mas um lugar que é produzido a partir das práticas dos seus habitantes. Foi a partir da pesquisa etnográfica que Devos, Coutinho e Verdana identificaram o papel cumprido pelos pescadores de tainha na formação criativa da paisagem litorânea, a partir das próprias temporalidades mobilizadas pela pesca, e dos relatos produzidos por eles.

Em seguida, no capítulo "Participação pública no processo de tomada de decisão para as ações das políticas de planejamento no litoral sul de Santa Catarina, Brasil”, Neres de Lourdes da Rosa Bitencourt reflete sobre conflitos e problemas socioambientais decorrentes do uso e ocupação do solo na região costeira do extremo sul catarinense, destacando a participação da sociedade na construção de políticas de planejamento territorial e gestão ambiental. Para isso, Bitencourt analisa instrumentos como a Agenda 21 Catarinense, Projeto Orla, Plano Estadual de Gerenciamento Costeiro de Santa Catarina e o Plano Diretor, e 
identifica o nível de participação, as percepções e discursos das populações locais sobre estes projetos, assim como sobre o meio ambiente que habitam.

No texto "A água só falta falar: memória, patrimônio ambiental e transformações na ocupação de áreas úmidas na cidade de Manaus, AM” Marcia Regina Calderipe Farias Rufino identifica intersecções entre memória e patrimônio ambiental junto com os moradores de igarapés de Manaus. Esta urbe amazônica foi construída sob uma visão modernista que viu aos igarapés como um impedimento para o avanço e embelezamento da cidade, sendo sua ocupação julgada e estigmatizada. A autora, ao longo do seu trabalho, destaca a necessidade de expandir a concepção do 'habitar', considerando neste contexto as trajetórias dos moradores dos igarapés, assim como as redes de relações criadas que dão sentido à sua existência na cidade.

Por último, a Parte IV "Educação Intercultural e Cosmologias” começa com o capítulo "A Licenciatura Intercultural Indígena do Sul da Mata Atlântica da UFSC em algumas incursões quanto a percepções e atuações territoriais dos/com Guarani, Kaingang e Laklãnõ-Xokleng” escrito por Maria Dorothea Post Darella. Ao longo do texto, a autora apresenta vários aspectos desta Licenciatura Indígena, cujo foco é trabalhar a questão fundiária e ambiental no bioma da Mata Atlântica, assim como os direitos territoriais e educativos das populações Guarani, Kaingang e Laklãnõ-Xokleng. Adicionalmente, a autora contextualiza a história das diretrizes que fundamentam as Licenciaturas Interculturais Indígenas no Brasil, a Pedagogia da Alternância como metodologia7, e expõe alguns obstáculos que surgem quando é confrontada a ciência como forma de conhecimento e a burocracia como método de controle político.

Em seguida, o antropólogo tukano João Rivelino Rezende Barreto, em "Educação Intercultural e o Intercâmbio de conhecimento indígena", parte do desafio que representa o diálogo intercultural para a educação indígena, admitindo que este também involucra outros espaços e sujeitos fora do mundo acadêmico. Por outro lado, o autor, no seu papel de professor e coordenador pedagógico da Licenciatura Intercultural do Sul da Mata Atlântica da UFSC, verificou que tinha um papel sumamente importante no uso da interculturalidade - deste uma perspectiva indígena ${ }^{8}$ - nesta pós-graduação, já que devia auxiliar aos alunos a criarem pontes entre a cultura acadêmica apreendida e os conhecimentos da sua própria cultura, adquirindo assim outros instrumentos conceituais, formas de pensar e sentir.

No capítulo "Práticas escritas em contexto multilíngue: política linguística e promoção das línguas indígenas na licenciatura da UFAM em São Gabriel da Cachoeira, AM”, Frantomé Bezerra Pacheco apresenta a Licenciatura Indígena da UFAM Políticas Educacionais e Desenvolvimento Sustentável, assim como a adoção do previsto nas leis 145 de 11/12/2002 e 210 de 31/10/2006, que pressupõe a cooficialização das línguas Nheengatu, Tukano e Baniwa. Dentro desta Licenciatura Indígena, as atividades didáticas e de pesquisa são realizadas majoritariamente nestas três línguas indígenas, enquanto o português assume um papel funcional e intermediário. Adicionalmente, esta licenciatura tem contribuído com a criação de glossários que fundamentam a escrita destas línguas indígenas, fortalecendo e revitalizando os conhecimentos transmitidos de forma oral.

\footnotetext{
7 Conformada pelo Tempo Universidade - TU, referente a períodos presenciais e intensivos na instituição universitária ou em escolas indígenas, e o Tempo Comunidade - TC, destinado a estudos orientados, projetos de pesquisa e intervenção comunitária, onde participam sábios especialistas indígenas.

8 Para Barreto, a Interculturalidade desde uma perspectiva indígena oferece "abertura ao conhecimento de culturas diferentes que possibilita uma melhor compreensão de sua própria cultura” (2017: 266), preparando assim aos alunos tanto para o contexto urbano, quanto para a sua realidade sociocultural.
} 
No último capítulo do livro titulado "Os indígenas Pankararu e a educação intercultural na cidade de São Paulo”, Marcos Alexandre dos Santos Albuquerque e Edson Yukio Nakashima apresentam um pouco sobre a migração deste povo a São Paulo, e sobre o papel da educação diferenciada como ferramenta para trabalhar com/sobre esta temática. Conforme os autores, a presença indígena no ambiente urbano gera questionamentos por parte da sociedade civil, sendo julgados por não corresponder com características genéricas e anacrônicas que lhes são outorgadas. Diante disso, surge um processo de etnogênese a partir do qual "uma comunidade ou povo passa a reivindicar sua diferença étnica em relação à sociedade nacional com base em determinada herança sociocultural" (Albuquerque \& Nakashima, 2017: 303), reelaborando símbolos e tradições culturais, algumas apropriadas do processo de colonização e redefinidas a partir da perspectiva indígena.

A partir dos trabalhos apresentados no livro "Saberes e Ciência Plural: Diálogos e Interculturalidade em Antropologia” é possível reconhecer a importância da pesquisa etnográfica para identificar conhecimentos que muitas vezes passam despercebidos por outras metodologias cientificas, valorizando as narrativas que exemplificam as práticas cotidianas que dão sentido à realidade. Além disso, a etnografia possui uma forte capacidade de ação política, considerando que pode auxiliar na elaboração de ações sociais que correspondam com a realidade sociocultural das populações estudadas.

Recebido em 29 de janeiro de 2019.

Aprovado em 11 de maio de 2019.

\section{Referências}

DEGREGORI, Carlos; SANDOVAL, Pablo. (org.) Presentación. In:

Saberes periféricos: ensayos sobre la antropologia em América Latina. Lima: IEP, 2008, 9-10.

KROTZ, Esteban. La producción de la antropología en el Sur: características, perspectivas, interrogantes. Alteridades. Ciudad de México, Universidad Autónoma Metropolitana Unidad Iztapalapa, v. 3, n. 6, 1993, p. 5-11.

OLIVEIRA, Roberto Cardoso de. O movimento dos conceitos na antropologia. Revista De Antropologia, n. 36, 1993, p. 13-31.

WALSH, Catherine. Interculturalidad crítica y pedagogía de-colonial: apuestas (des) de el in-surgir, re-existir y re-vivir. UMSA Revista (entre palabras), n. 3, 2009. 